\title{
Study of some demographic parameters of Bactrocera (Dacus oleae); Test of a new food attractant in a trapping method
}

\author{
A. Achouche ${ }^{1,2}$, F. Abbassi ${ }^{1}$, A. Benzahra ${ }^{1}$, Z. Djazouli ${ }^{2}$ \\ ${ }^{1}$ Department of Agricultural and Forestry Zoology, Ecole Nationale Supérieure Agronomique, Avenue Hassan Badi El \\ Harrach Algiers, Algeria. \\ ${ }^{2}$ Department of Sciences of Nature and Life, Biotechnology Laboratory of Plant Productions, University of Blida 1. B.P. \\ 270 Soumaa Road; Ouled yaich Blida, Algeria.
}

Tel: (213) 238285 07/12; E-mail: rahim1111149@hotmail.fr

Received: 02.07.2019. Accepted: 31.07.2019

This study focuses on the observation of changes in the demographic parameters of olive fly over time in two regions, Mitidja and Mezghana region, the method consists in identifying certain biotic and abiotic factors that can play a role on the variations of these parameters; on the other hand we tested new food attractiveness in a trapping method.

The Results showed that the demographic parameters (emergence, parasitism and mortality) are influenced by the year and by the region factor with a very high emergence rate above 50\%; On the other hand, the rate of parasitism remains low with a maximum value of $33.23 \%$ recorded in Mezghenna, regarding nymphal mortality the maximum value is recorded in Chebacheb with $26.44 \%$.

Furthermore, the study of the efficiency of nitrogen fertiliser (Urea 46 unit) on the catches of adults showed us that the best concentration of attraction is 6\%; on the other hand, the yellow color of the traps positively influences the catches of Bactroceraoleae.

Keywords: Mitidja; mezghenna; nitrogen fertilizer; Bactrocera oleae

\section{Introduction}

In Algeria, Arboriculture is dominated by olive tree that stretches around nearly 315000 ha, with millions of olive trees, according to (ITAFV, 2015), with an annual production of 47473 ton of Olive and 9351 cubic meter of Olive Oil (ONFA, 2015). Despite, all this important supply of Olive Tree, the Algerian Inland trade market is not satisfied (ITAFV, 2015).

Olive Tree is susceptible to attacks of several pests, indeed, it is considered home to a quite rich and diversified fauna, including notorious phytophagous species, in which the economic damages often require interventions to save both quantitative and qualitative production (Hamiche et al., 2004).

Bactrocera oleae (Diptera, Tephritidae), commonly known as Olive fruit fly, is considered the most serious pest in the cultivation of olive in Mediterranean Basin counties (Economopoulos, 2002; Danne et al., 2010; Skouras et al., 2007; Arambourg, 1986). Also in Southern Europe, Middle east and along the East coast of Africa to South Africa, This fly can develop and survive in any region in the world olive is grown (Elmessoussi et al., 2010).

The caused damages mean an economic sanction in terms of both quantity and quality. Quantitative damages are more pronounced when the Larva complete its development cycle, which boil down to the removal of the significant proportion of the pulp, caused by the Larvae and the premature falling of the fruit (Cimato, 1990). Qualitative changes of oil have been most studied by many researchers (Malheiro et al., 2016; Gucci et al., 2012; Mraicha et al., 2010).

The activity of the olive fruit fly is due to several factors including Latitude, Altitude, what the tree contains, Irrigation (Neuenschwander et al., 1986), temperature (Raspi et al., 2005; Genç et al., 2008), Relative Humidity (Broufas, 2009), the Variety (Rizzo et al., 2006), the Physicochemical Characteristic of the Drupe (Mraicha et al., 2011) and the activity of parasites (Kapaun et al., 2010 ) etc.

According to (Belhoucine, 2003), an optimal integration of the Fruit flies control methods, cannot be fulfilled without an understanding of the biology of their population, in particular their dynamic.

Until the moment, the majority of information on the fluctuation in the population of these insects is based on the trapping of adults. However, these data have only a relative importance and reliability as the captures adults represent only a part of the population ( Kapatos, 1989).

In Algeria, the study ofthe olive flybioecologyis not very well known. For these reasons, we thought it important to follow the evolution of the olive fly in time in two regions, the Mitidja region that was represented by three stations (Chebacheb (a); Meftah (b) and OuledYaiche (c)), and the Mezghana (d) region. 
In our study, we tried to identify certain biotic and abiotic factors that can play on the demographic parameters of the olive fly; on the other hand, we tested a new food attractant in a trapping method.

\section{Materials and methods}

\section{Geographical location of the study areas}

The Mitidja area: The Mitidja is a vast plain south of Algiers, its area is about $1400 \mathrm{~km}^{2}$ ( Hadjoudji, 2014; Kayser, 1980; Baha, 1997), elongated, it extends about hundred kilometers from Est to West, and ranging in width from 5 to $20 \mathrm{~km}$. Bordered by two high terrains. The hills of the Algerian Sahel in north, and by the Atlas Blideen in south. From west to Est, the plain crosses the following prefectures Tipaza, Blida, Algiers and Boumerdes. It is situated between longitudes $2^{\circ} 32^{\prime} 00$ to $3^{\circ} 19^{\prime} 00$ and latitudes $36^{\circ} 25^{\prime} 17$ to $36^{\circ} 47^{\prime} 40$ (Sbargoud, 2016).

This region is considered as potential abricultural area. Indeed, trees statistics show the existence of several species and verities of fruit trees such as citrus, olive, vine, apricot, peach and fig...etc. The experimental work in Mitidja took place in three sites, first site is Chebacheb (a), it is located $25 \mathrm{~km}$ southeast the capital Algiers, the second site (b) took place in the municipality of Meftah $41 \mathrm{~km}$ from Blida, the last site (c) took place in OuledYaichein the experimental area of Saad Dahleb University.

The Mezghanna area: The municipality of Mezghana is located in the Tellian Atlas centre, with an average altitude of $450 \mathrm{~m}$ and $700 \mathrm{~m}$, a typical Mediterranean climate with annual rainfall of $641 \mathrm{~mm}$ and an average temperature of $8{ }^{\circ} \mathrm{C}$ in winter and $24.5^{\circ} \mathrm{C}$ in summer.

As a relief, relatively high slopes characterize this area, bordered by five communes, Tablat and Aissaouia in the North, Bouchrahil in the East, SidiErrabie in the South and Mihoub municipality in the West.

The flora of the study area, initially, from implanted vegetables, exotic and indigenous plants, mainly represented by Cedrus AtIntica, was later enriched by tree species such as the olive tree, almond tree, fig tree and vine... etc. this vegetation cover allowed wildlife, such as birds, snakes, arthropods, and mammals to colonize the environment. The experimental work in Mezghana commune was conducted at a single site (d) which is located on the eastern side of the region'(Figure 1).

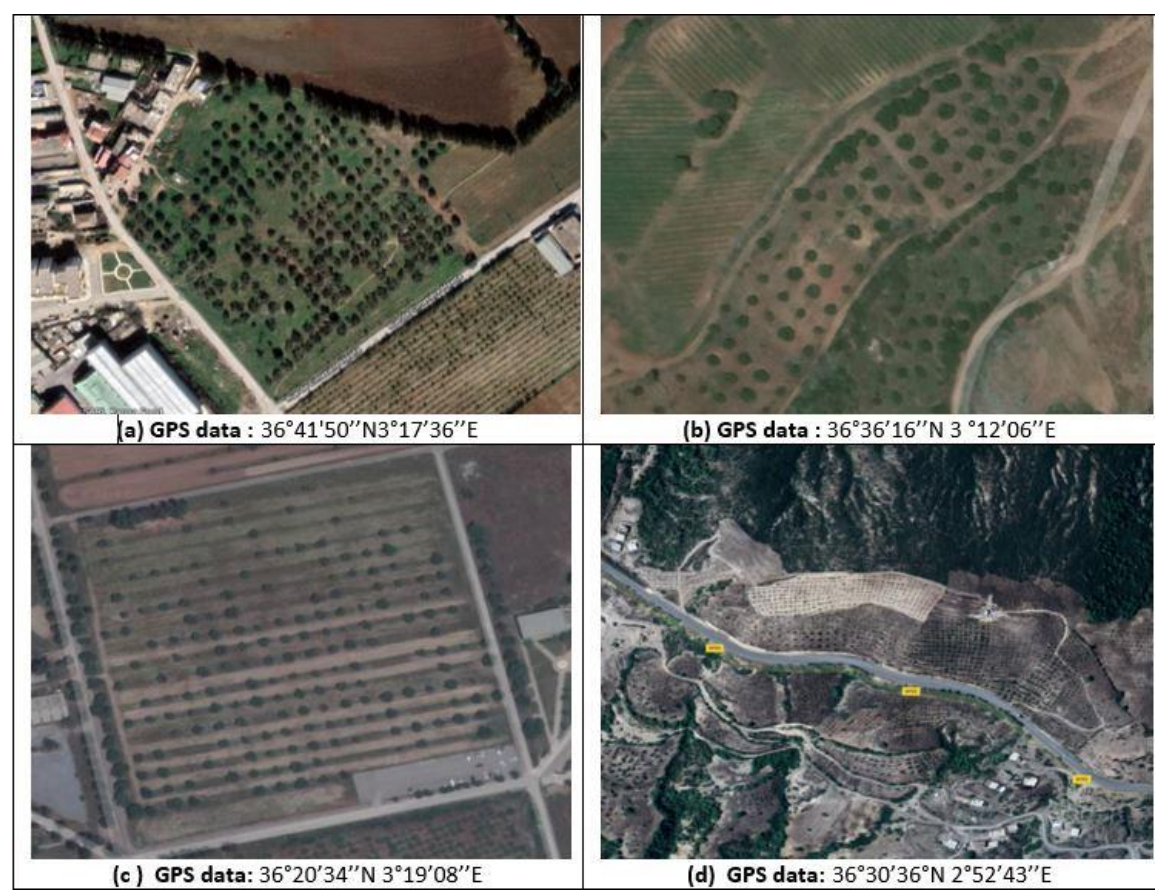

Figure 1. Geographical location of the study area.

Climate of study area: The climate of the study areas belongs to the warm temperate or temperate climate family. Rain falls mainly in winter, with a relatively little rain in summer. The classification of Köppen-Geiger is of type Csa (Mediterranean climate was hot) (Figure 2). 


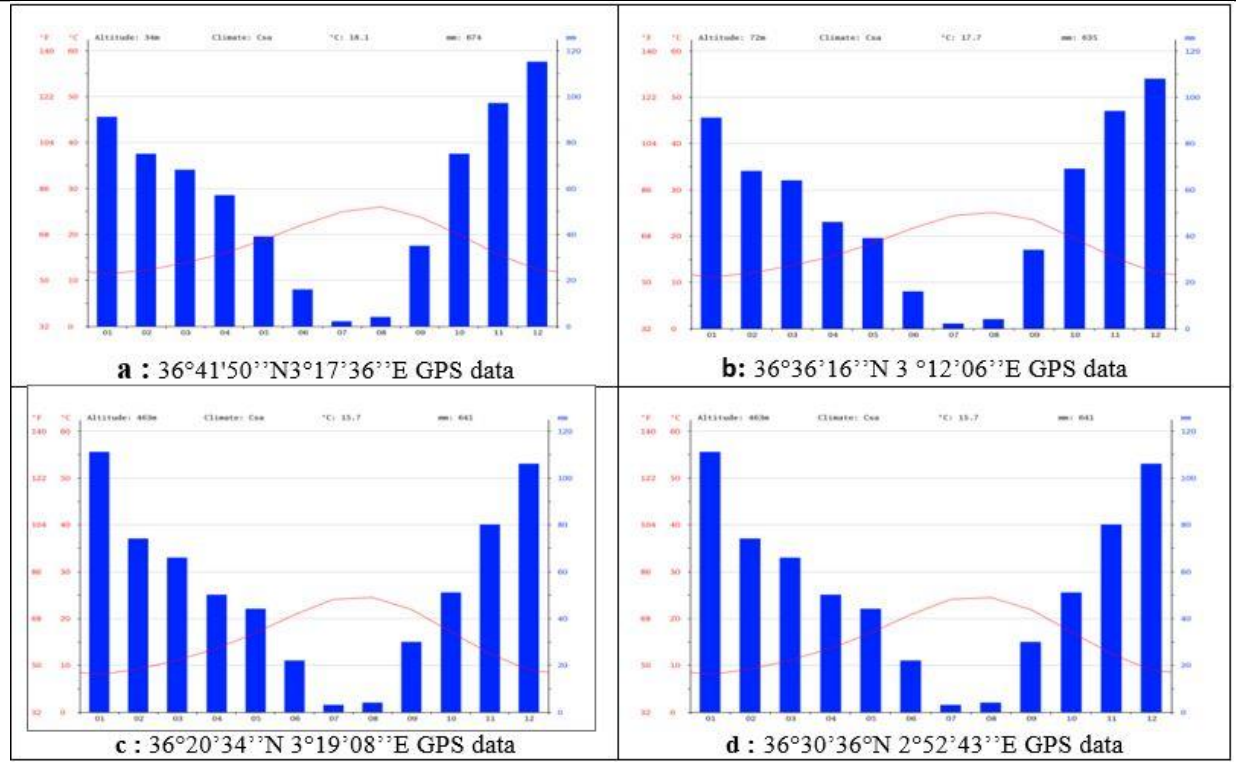

Figure 2. Climatic chart of study areas; a: Chebacheb; b: Meftah; c: Ouled Yaiche; d: Mezghenna.

\section{Follow-up of incubations and hatching of pupae}

The work and the survey data of (Medjdoub, 2010; Belhoucine, 2003); formed the basis of this study to estimate the rate parasitism of $B$. oleae, and whether there is a biological control. The simplest method consist in taking samples of olive, breeding them to count the flies and parasites that emerge in. For this reason, we have collected 300 olive fruit each month during the whole period of ripening of fruits (in 2016 and 2017) in each olive grove. The harvested olives are deposited inside cans, while pupae are counted and deposited as in pillboxes and petri dishes during the breeding period.

Two weeks later, the emergence of adults is controlled regularly. We enumerate flies and parasitoides emerged to assess the rate of parasitism and the nature of the parasitoide. Also, Farms allow to estimate survival and therefore mortality rated pupae.

\section{Study of the effectiveness of nitrogen fertiliser on adult catches}

The study of the efficacy of nitrogen fertiliser on the olive fly monitoring was carried out in the Mezghannaregion of Medea. The working method is based on the use of yellow food traps containing chemical attractants (nitrogen fertilizers) in order to collect flies to limit their population and descendants.We installed 4 food traps for each concentrations of fertilizer(0\%; $2 \%$; $3 \% ; 6 \%$ and $9 \%$ ).

\section{Study of the influence of traps colors on adult catches}

This study is based on comparing adult catches of olive fly in food traps of deferent colors (yellow and transparent); we installed four baited traps with $3 \%$ of nitrogen fertilizer for each trap type.

\section{Results and discussion}

\section{Follow-up of incubations and hatching of pupae}

Variation in percentage of different demographic parameters (emergence of olives, nymphal mortality, parasitism) in the Mediterranean climate of the CSA type (Figure 3 and Table 1).

The study of the emergence of Bactrocera oleae in the climate type Csa showed a very high percentage in 2017 with about 80\%; Moreover we observed a low parasitism rate varies between $6.5 \%$ in 2017 and $27.15 \%$ in 2018 .For mortality, we recorded an average rate lower than $20 \%$ throughout the whole study period.

Variation in percentage of the different demographic parameters (Emergence of B oleae; Nymphal mortality; Parasitisme ) in the different study area (Figures 4-6; Table 2).

According to the study areas, the highest rate of parasitism is recorded in Mezghana (D) with 33.23\%, followed Ouledyaiche (c) with 21.49\%, while in Meftah (a) and Chebacheb (a) the percentage is less than 10\% (Figure 5, Table 2).

As regards the emergence of the Bactrocera olea, we observed a rate above $50 \%$ in all regions, while the Metfah olive grove (B) recorded the highest percentage with $82.26 \%$ (Figure 5; Table 2).

Returning to Nymphal mortality, (Figure 6; Table 2), the observation of deferent percentages of mortality showed that Chbacheb's Olive Grove (a) was most affected with $26.44 \%$, followed Ouledyaiche station with $15.57 \%$, for aillor, Meftah (b) and Mezghana (d) respectively recorded very low rates, of about $10.45 \%$ and $10 \%$.

\section{The Effect of climate factors on the demographic parameters}

The regional climate acts as a favorable factor limiting the numerical abundance of populations (Benassy, 1975). Temperature is the most important factor in weathering (Dreux, 1980). It determines the distribution and reproduction of botanical and animal species (Benassy, 1975; Heie, 1987). Temperature variations determine vertical and seasonal migration of populations (Claude et al., 1984). Temperatures fluctuate continuously, at all time and space scales. For insects, there is always a thermal preferendum allows them to choose their biotope.

The demographic characteristics of host-parasitoid relationships 
There is a considerable amount of work, sometimes experimental but often theoretical, which sought to describe, understand and therefore explain the temporal fluctuations in the numbers of parasitoids and their hosts. There are several reasons for this decades-long research effort.The first is that the ecological characteristics of the functioning of parasitoids, as they have just been quickly described above, lend themselves quite easily to mathematical formalization.For example, unlike predators, only adult females search for and attack hosts.Moreover, since the laying of an egg causes the death of the attacked host in all cases, there is a direct link between the effectiveness of parasitoid female research and the mortality rate of the hosts.As well as, the reproductive efficiency of parasitoid females is directly related to the number of hosts attacked. Finally, the host and the parasitoid most often have similar generation times.Another reason relates to the use of parasitoid insects in crop protection to control crop insect pests; in this case, the objective is to reduce the number of hosts. A detailed understanding of the demographic mechanisms involved in relations between the two partners is essential in this respect (Wajnberg, 2012).

Table 1. Percentage of the different demographic parameters (Emergence of B oleae; Nymphal mortality; Parasitisme) in the Mediterranean climate type CSA.

\begin{tabular}{lll}
\hline Demographic parameter \% & $\mathbf{2 0 1 7}$ & $\mathbf{2 0 1 8}$ \\
Emergence of B oleae\% & 79.8 & 53.4 \\
Nymphal mortality\% & 13.7 & 19.4 \\
Parasitism\% & 6.5 & 27.2 \\
\hline
\end{tabular}

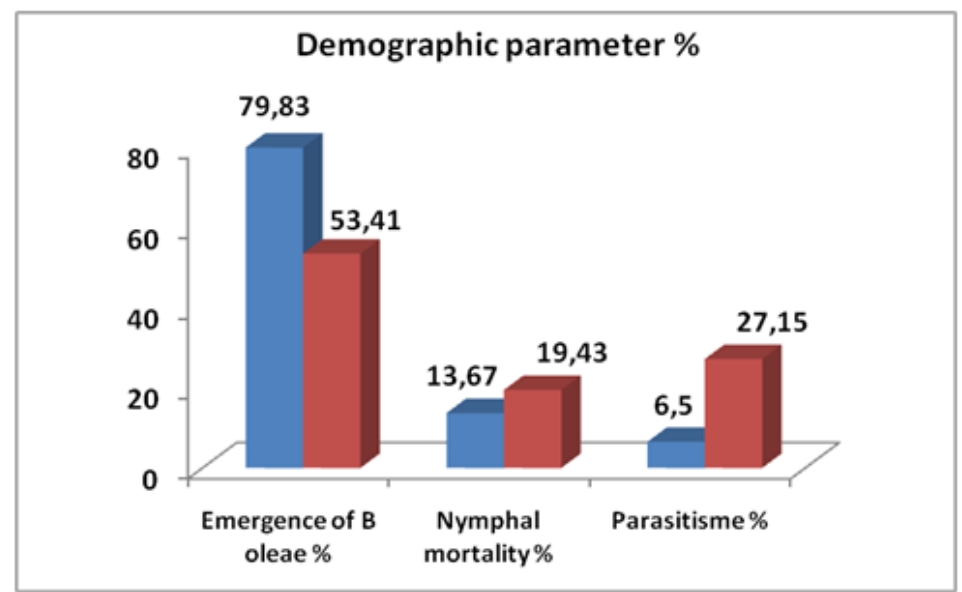

Figure 3. Average percentage of the different demographic parameters (Emergence of B oleae; Nymphal mortality; Parasitisme ) in the Mediterranean climate type CSA.

Table 2. Percentage of the different demographic parameters (Parasitisme; Emergence of B oleae and Nymphal mortality) in the different study area.

\begin{tabular}{llll}
\hline Region & Parasitism \% & Emergence of Bactrocera oleae \% & Nymphal Mortality \% \\
Chebacheb (a) & 9.75 & 63.81 & 26.44 \\
Meftah (b) & 7.29 & 82.26 & 10.45 \\
Ouled Yaiche (c) & 21.49 & 62.94 & 15.57 \\
Mezghenna (d) & 33.23 & 56.77 & 10 \\
\hline
\end{tabular}

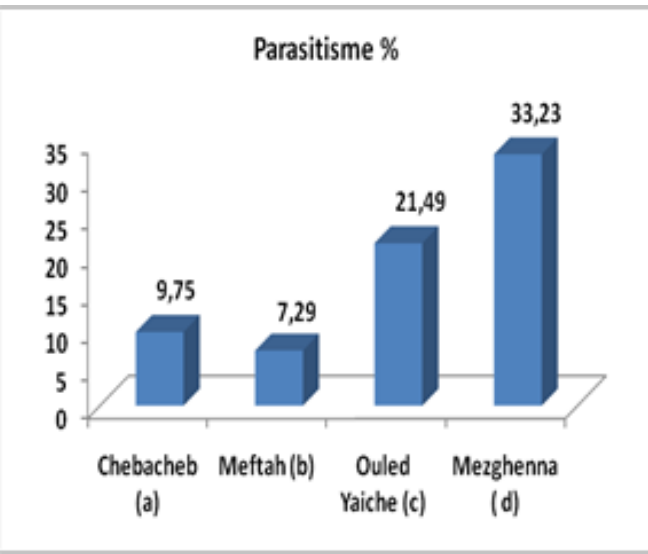

Figure 4. Average percentage of parasitism in the different study areas (\%). 


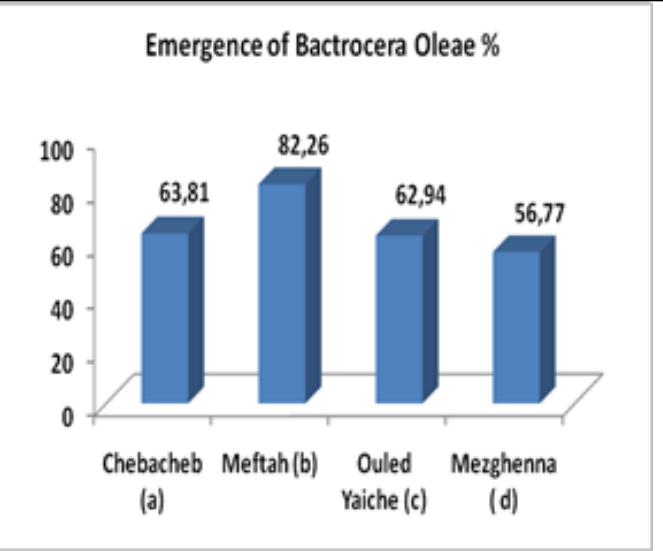

Figure 5. Average percentage of emergence of Bactrocera oleae.

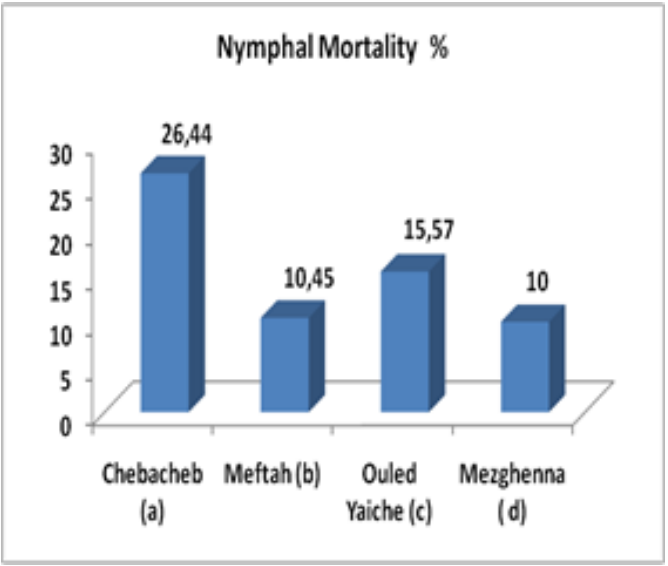

Figure 6. Average percentage of nymphal mortality in the different study area (\%).

\section{Parasitoide identification}

This study is a permis of identifier in parasitoïde from the family of Braconidae, Opius concolor, This species was placed in the subgenus Psyttalia by (Fischer, 1987) and subsequently elevated to generic rank by (Wharton, 1987). Most of the countries that suffer from $B$. oleae damage have conducted studies on the rearing of $P$. concolor for use in biological control of the pest (Biliotti and Delanoue, 1959; Jannone and Binaghi, 1959; Avilla and Albajes, 1983; Raspi and Loni, 1994).

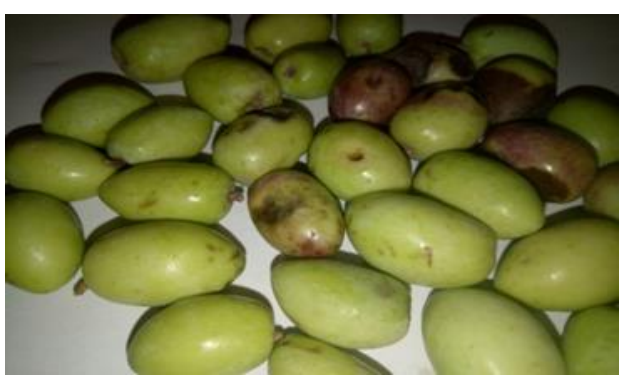

Figure 7. Olive fruit attacked by Bactrocera oleae.

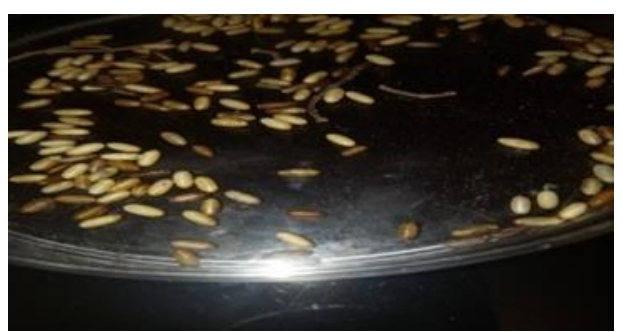

Figure 8. Nymphs of Bactrocera oleae after incubation. 


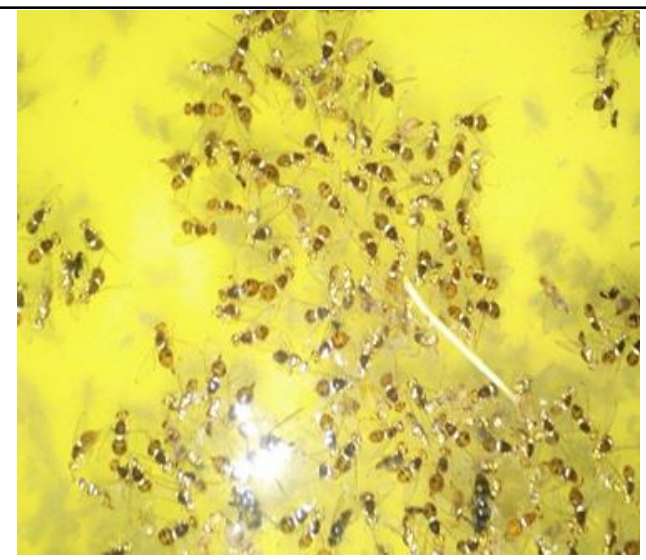

Figure 9. Bactrocera oleae.

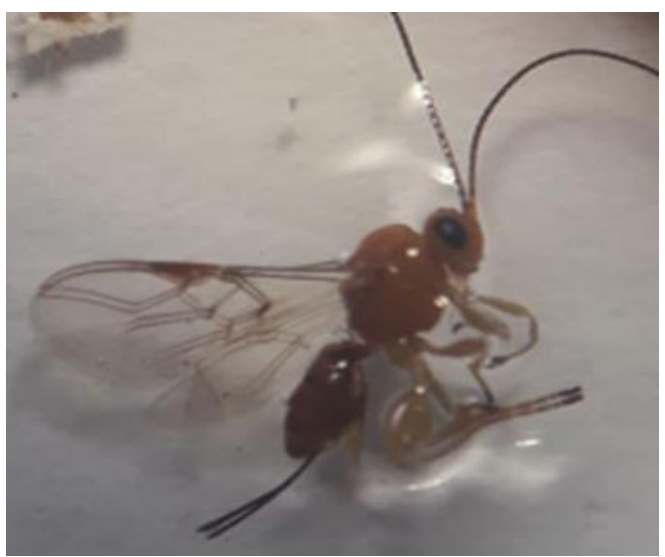

Figure 10. Psyttalia (Opius) concolor.

Variation in olive fruit fly catches as a function of nitrogen fertilizer (urea 46 units) concentration and the color of food traps (Figures 7-10, Table 3):

The results showed that the catch of the diptera increases with the concentration of the attractant (nitrogen fertilizer), the maximum value is recorded at 6\% with 152 flies; Beyond this concentration we observed a decrease in catches of Bactroceraoleae, 113 individuals were caught at $9 \%$ fertilizer.

Regarding the color effect of the traps on the attraction of the olive fly, comparison of yellow and transparent traps that baited with $3 \%$ fertilizer showed that the color of the traps positively influences diptera catches (146 flies for yellow traps and 70 flies for transparent traps) (Figure 11).

Table 3. Variation in olive fruit fly catches as a function of nitrogen fertilizer concentration and the color of food traps.

\begin{tabular}{|c|c|c|c|c|c|c|c|}
\hline \multirow{2}{*}{$\begin{array}{l}\text { Concentration of nitrogen fertilizer (Urea 46) } \\
\%\end{array}$} & \multicolumn{5}{|c|}{ Yellow food trap } & \multirow{2}{*}{\multicolumn{2}{|c|}{$\begin{array}{l}\text { Transparent } \\
\text { trap } \\
3 \% \text { (c6) }\end{array}$}} \\
\hline & $\begin{array}{l}0 \% \\
\text { (c1) }\end{array}$ & $\begin{array}{l}2 \% \\
\text { (c2) }\end{array}$ & $\begin{array}{l}3 \% \\
\text { (c3) }\end{array}$ & $\begin{array}{l}6 \% \\
\text { (c4) }\end{array}$ & $\begin{array}{l}9 \% \\
\text { (c5) }\end{array}$ & & \\
\hline Catch number of the olive fruit fly & 2 & 96 & 146 & 152 & 113 & 70 & \\
\hline
\end{tabular}

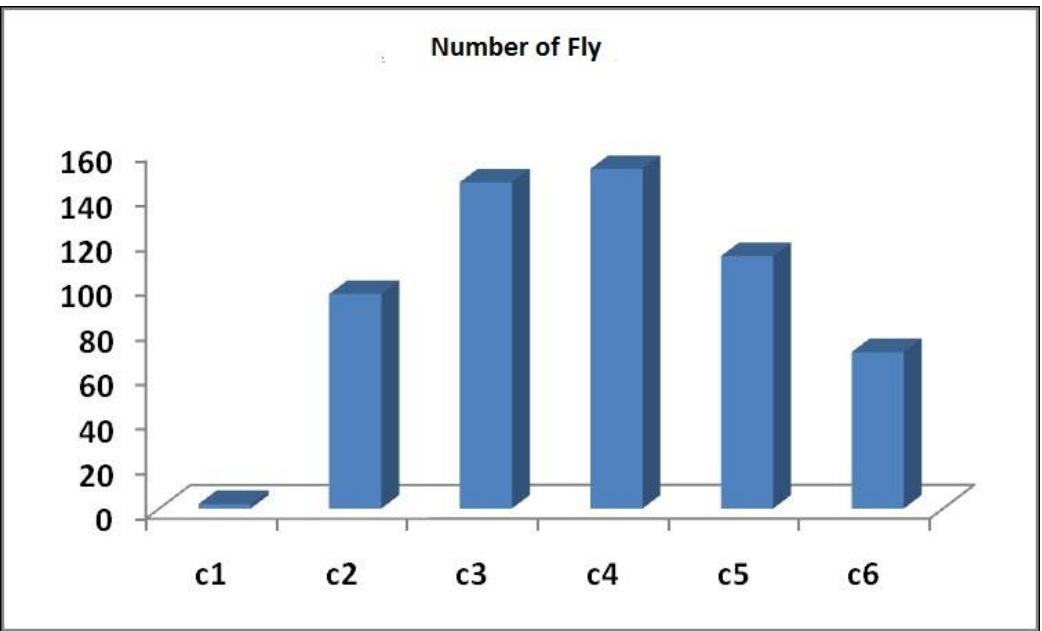

Figure 11. Variation in olive fruit fly catches as a function of nitrogen fertilizer concentration and the color of food traps. 


\section{Conclusion}

The demographic parameters of Bactroceraoleae were studied for two years in 2017 and 2018; the follow-up of incubations and the outbreak of pupae allowed us to retain several points:

- Psytallia (Opius) concolor was the only parasitoid observed throughout the study period.

- The variation in deferential parameters in the Mediterranean climate type, CSA showed us that there is always an annual change in the emergence of parasitism and nymphal mortality.

- Variation of deferential endpoints across study areas explained the effect of microclimate on the dynamics of Bactrocera oleae population parameters.

Furthermore, the study of the efficiency of nitrogen fertiliser (Urea 46 unit) on the catches of adults showed us that the best concentration of attraction is 6\%; on the other hand, the yellow color of the traps positively influences the catches of Bactroceraoleae.

\section{References}

Arambourg, Y. (1986). Traité d'entomologie oléicole. Conseil Oléicole International.

Avilla, J. E., \& Albajes, R. (1984). The influence of female age and host size on the sex ratio of the parasitoid Opius concolor. Entomologia Experimentalis et Applicata, 35(1), 43-47.

Baha, M. (1997). The earthworm fauna of Mitidja, Algeria. Tropical Zoology, 10(2), 247-254.

Belhoucine, S. Etude de l'éventualité d'un contrôle biologique contre la mouche de l'olive Bactrocera oleae (DipteraTephritidae) dans cinq stations de la wilaya de Tlemcen (Doctoral dissertation).

Benassy, C. (1975). Les cochenilles des agrumes dans le bassin méditerranée. Ann Inst Nat Agro, EL-HARRACH, 5(8), 118142.

Boukoftane, A., \& Benrima, A. (2018). Effet des facteurs climatiques sur la répartition spatiotemporel des pucerons d'agrumes en Mitidja centrale (Algérie) 8(1): 958-966.

Biliotti, E., \& Delanoue, P. (1959). Contribution a l'etude biologique d'Opius concolor Szepl.(Hym. Braconidae) en elevage de laboratoire. Entomophaga, 4(1), 7-14.

Hepdurgun, B., Turanli, T., \& Zumreoglu, A. (2009). Parasitism rate and sex ratio of Psyttalia (= Opius) concolor (Hymenoptera: Braconidae) reared on irradiated Ceratitis capitata larvae (Diptera: Tephritidae). Biocontrol Science and Technology, 19(sup1), 157-165.

Broufas, G. D., Pappas, M. L., \& Koveos, D. S. (2009). Effect of relativehumidity on longevity, ovarian maturation, and egg production in the olive fruit fly (Diptera: Tephritidae). Annals of the Entomological Society of America, 102(1), 70-75.

Cimato, A. (1990). La qualité de l'huile d'olive vierge et les facteurs agronomiques. Olivae, 31, $20-31$.

Belhoucine, S. Etude de l'éventualité d'un contrôle biologique contre la mouche de l'olive Bactrocera oleae (DipteraTephritidae) dans cinq stations de la wilaya de Tlemcen (Doctoral dissertation).

Claude, F., Christiane, F., \& Paul, M. (1984). Ecologie. 3, 162.

Boukoftane, A., \& Benrima, A. (2018). Effet des facteurs climatiques sur la répartition spatiotemporel des pucerons d'agrumes en Mitidja centrale (Algérie). 8(1), 958-966.

Daane, K. M., \& Johnson, M. W. (2010). Olive fruit fly: managing an ancient pest in modern times. Annual review of entomology, 55, 151-169.

Dreux, P. (1980). Précis d'écologie. Presses Universitaires de France, Paris, 231 p.

Economopoulos, A. P. (2002). The Olive Fruit Fly, Bactrocera (Dacus oleae) (Gmelin) (Diptera: Tephritidae): Its Importance and Control; Revise SIT Research and Pilot Testing. Report to International Atomic Energy Agency (IAEA), Vienna, Austria, 44.

Genc, H. (2008). Modified agar-based diet for small scale laboratory rearing of olive fruit fly, Bactrocera oleae (Diptera: Tephritidae). Florida Entomologist, 651-656.

El Messoussi, S. C., Mohammed, A. M., \& Lahrouni, A. (2010). Vers une modélisation de la dynamique de la population de la mouche Bactrocera oleae, Série Zoologie, 47, 77-80.

Fischer, M. (1987). Hymenoptera, Opiinae III: Äthiopische, orientalische, australische und ozeanische Region. Das Tierreich, 104, 1774.

Genç, H., \& Nation, J. L. (2008). Survival and development of Bactrocera oleae Gmelin (Diptera: Tephritidae) immature stages at four temperatures in the laboratory. African Journal of Biotechnology, 7(14).

Gucci, R., Caruso, G., Canale, A., Loni, A., Raspi, A., Urbani, S., Taticchi, A., Esposto, S., \& Servili, M. (2012). Qualitative changes of olive oils obtained from fruits damaged by Bactrocera oleae (Rossi). HortScience, 47(2), 301-306.

Hadjoudj, O., Bensemmane, R., Saoud, Z., \& Reggabi, M. (2014). Pollution des eaux souterraines de la mitidja par les nitrates: État des lieux et mesures correctives. European journal of water quality, 45, 57-68.

Hamiche, A., and Doumandji, S. ( 2014). Olive fruit infestation by Bactrocera oleae Gmelin and Rossi, 1788 (DipteraTephritidae) in three biotopes of Grande Kabylie (Algeria), International Journal of Zoology and Research, 4(6), 11-18.

Heie, O. E. (1987). Palaeontology and phylogeny in Aphis, their biology, natural enemies and control. Elsevier, 2A, $367-392$. Boukoftane, A., \& Benrima, A. (2018). Effet des facteurs climatiques sur la répartition spatiotemporel des pucerons d'agrumes en Mitidja centrale (Algérie), 8(1), 958-966.

ITAFV. (2015). La culture de l'olivier. Collection du Cinquantenaire. Algérie. 
Jannone, G., and Binaghi, G. (1959). Primi esperimenti di introduzione in Liguria di un endofago della mosca delle olive: Opius concolor Szépl.(=O. siculus Mon.)(Hymenoptera: Braconidae) della Sicilia. Boll. Lab. Entomol. Agr. Portici, 17, 89123.

Hepdurgun, B., Turanli, T., \& Zümreoğlu, A. (2009). Parasitism rate and sex ratio of Psyttalia (= Opius) concolor (Hymenoptera: Braconidae) reared on irradiated Ceratitis capitata larvae (Diptera: Tephritidae). Biocontrol Science and Technology, 19(sup1), 157-165.

Kapatos, E. T. (1989). Integrated pest management systems of Dacus oleae. Fruit Flies. Their biology, natural enemies and control. B, 3, 391-396.

Belhoucine, S. Etude de l'éventualité d'un contrôle biologique contre la mouche de l'olive Bactrocera oleae (DipteraTephritidae) dans cinq stations de la wilaya de Tlemcen (Doctoral dissertation).

Kapaun, T., Nadel, H., Headrick, D., \& Vredevoe, L. (2010). Biology and parasitism rates of Pteromalus nr. myopitae (Hymenoptera: Pteromalidae), a newly discovered parasitoid of olive fruit fly Bactroceraoleae (Diptera: Tephritidae) in coastal California. Biological control, 53(1), 76-85.

Malheiro, R., Casal, S., Cunha, S. C., Baptista, P., \& Pereira, J. A. (2016). Identification of leaf volatiles from olive (Olea europaea) and their possible role in the ovipositional preferences of olive fly, Bactrocera oleae (Rossi)(Diptera: Tephritidae). Phytochemistry, 121, 11-19.

Meziani, M. K.( 2010). Stratégie de défense biochimique mise en œuvre par les olives attaquées par le ravageur Bactrocera oleae (Diptera - Tephritidae) dans la région d'Oudjlida (Wilaya de Tlemcen). Thèse Magister, Université Abou Bakr Belkaid, Tlemcen.

Mraicha, F., Ksantini, M., Zouch, O., Ayadi, M., Sayadi, S., \& Bouaziz, M. (2010). Effect of olive fruit fly infestation on the quality of olive oil from Chemlali cultivar during ripening. Food and Chemical Toxicology, 48(11), 3235-3241.

Mraicha, F., \& Ksantini, M. (2011).Effet de la variété d'olivier et des caractéristiques physico-chimiques de la drupe sur le taux d'infestation par la mouche de l'olive, Bactrocera oleae (Diptera, Tephritidae). Revue Ezzaitouna, 12(1), 12.

Mutin, G. (1977). La Mitidja: décolonisation et espace géographique. Éditions du CNRS.

Neuenschwander, P., Michelakis, S., \& Kapatos, E. (1986). Tephritidae. Traite d'entomologie oleicole. International Olive Oil Council, Madrid, ES, 115-159.

ONFA (Observatoire national des filieres agricoles et agroalimentaires). (2016). Bilan de la campagne oléicole 2015/2016. Segment huile d'olive, pp: 1-13.

Raspi, A., Canale, A., \& Loni, A. (2005). Presence of mature eggs in olive fruit fly, Bactrocera oleae (Diptera tephritidae), at different constant photoperiods and at two temperatures. Bulletin of Insectology, 58(2), 125.

Raspi, A., \& Loni, A. (1994). Alcune note sull'allevamento di Opius concolor Szépl.(Hymenoptera Braconidae) e su recenti tentativi d'introduzione della specie in Toscana e Liguria. Frustula entomologica, 133-145.

Hepdurgun, B., Turanli, T., \& Zümreoğlu, A. (2009). Parasitism rate and sex ratio of Psyttalia (= Opius) concolor (Hymenoptera: Braconidae) reared on irradiated Ceratitis capitata larvae (Diptera: Tephritidae). Biocontrol Science and Technology, 19(sup1), 157-165.

Rizzo, R., \& Caleca, V. (2006). Resistance to the attack of Bactrocera oleae (Gmelin) of some Sicilian olive cultivars. In Proceedings of Olivebioteq 2006, Second International Seminar "Biotechnology and quality of olive tree products around the Mediterranean Basin". Mazara del Vallo, Marsala, Italy, 2, 291-298.

Sbargoud, S. (2013, April). Validité de l'application de la méthode de vulnérabilité DRASTIC à l'étude de la pollution par les nitrates dans la Mitidja (Nord d'Algérie). In Conférence GeoTunis, 8, 12.

Skouras, P. J., Margaritopoulos, J. T., Seraphides, N. A., Ioannides, I. M., Kakani, E. G., Mathiopoulos, K. D., \& Tsitsipis, J. A. (2007). Organophosphate resistance in olive fruit fly, Bactrocera oleae, populations in Greece and Cyprus. Pest Management Science: formerly Pesticide Science, 63(1), 42-48.

Wajnberg, E., \& Rice, N. (2012). Parasitisme et lutte biologique. In: Jean-François, G., Renaud, F., \& Thomas, F (Eds). Biologie Ecologie et Evolution des Systèmes Parasités ( $2^{\text {nd }}$ Edn). International Journal on Research and Development, 280.

Wharton, R. A. (1987). Changes in nomenclature and classification of some opiine Braconidae (Hymenoptera). Proceedings of the Entomological Society of Washington, 89(1), 61-73.

https://fr.climate-data.org

Citation: Achouche, A., Abbassi, F., Benzahra, A., Djazouli, Z. (2019). Study of some demographic parameters of Bactrocera (Dacus oleae); A test of a new food attractant in a trapping method. Ukrainian Journal of Ecology, 9(3), 13-20.

(cc) $\mathbf{E Y}$ This work is licensed under a Creative Commons Attribution 4.0. License 